\title{
Maternal and child factors associated with timely initiation of breastfeeding in sub- Saharan Africa
}

Francis Appiah 1,2, Bright Opoku Ahinkorah³, Eugene Budu', Joseph Kojo Oduro ${ }^{1}$, Francis Sambah ${ }^{4,5}$, Linus Baatiema', Edward Kwabena Ameyaw ${ }^{3}$ and Abdul-Aziz Seidu ${ }^{1,5,6^{*}}$ (D)

\begin{abstract}
Background: The probability of not breastfeeding within the first hour after delivery (timely initiation of breastfeeding) is particularly pronounced in sub-Saharan Africa. In this study, we examined the maternal and child factors associated with timely initiation of breastfeeding in sub-Saharan Africa.

Methods: We pooled data from 29 sub-Saharan African countries' Demographic and Health Surveys conducted from 2010 to 2018. A total of 60,038 childbearing women were included. Frequencies, percentages, and binary logistic regression analyses were carried out. Binary logistic regression was used to examine the maternal and child factors associated with timely initiation of breastfeeding and the results were presented as adjusted odds ratios (aOR) at 95\% confidence interval (Cl).

Results: We found a prevalence of $55.81 \%$ of timely initiation of breastfeeding in the sub-region. The country with the highest prevalence of timely initiation of breastfeeding was Burundi (86.19\%), whereas Guinea had the lowest prevalence (15.17\%). The likelihood of timely initiation of breastfeeding was lower among married women, compared to never married women (aOR 0.91; $95 \% \mathrm{Cl} 0.85,0.98$ ); working women compared to non-working women (aOR 0.90; 95\% Cl 0.87, 0.93); women who watched television at least once a week, compared to those who never watched television (aOR 0.74; 95\% Cl 0.70, 0.78); women who delivered through caesarean section, compared to vaginal birth (aOR 0.30; $95 \% \mathrm{Cl} 0.27,0.32$ ); and those with multiple births, compared to those with single births (aOR 0.67; 95\% Cl 0.59, 0.76). Women who lived in Central Africa were less likely to initiate

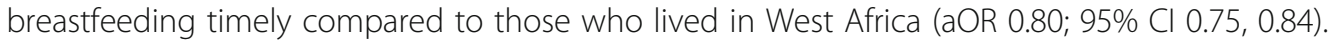

Conclusions: The findings call for the need for a behavioural change communication programmes, targeted at timely initiation of breastfeeding, to reverse and close the timely initiation of breastfeeding gaps stratified by the maternal and child factors. Prioritising policies to enhance timely initiation of breastfeeding is needed, particularly among Cental African countries where timely initiation of breastfeeding remains a challenge. Sufficient supportive care, especially for mothers with multiple births and those who undergo caesarean section, is needed to resolve timely initiation of breastfeeding inequalities.
\end{abstract}

Keywords: Maternal and child factors, Timely initiation of breastfeeding, SSA, DHS, Maternal health, Global health

\footnotetext{
* Correspondence: abdul-aziz.seidu@stu.ucc.edu.gh

'Department of Population and Health, College of Humanities and Legal

Studies, University of Cape Coast, Cape Coast, Ghana

${ }^{5}$ College of Public Health, Medical and Veterinary Sciences, James Cook

University, Townsville, Queensland, Australia

Full list of author information is available at the end of the article
}

(c) The Author(s). 2021 Open Access This article is licensed under a Creative Commons Attribution 4.0 International License, which permits use, sharing, adaptation, distribution and reproduction in any medium or format, as long as you give appropriate credit to the original author(s) and the source, provide a link to the Creative Commons licence, and indicate if changes were made. The images or other third party material in this article are included in the article's Creative Commons licence, unless indicated otherwise in a credit line to the material. If material is not included in the article's Creative Commons licence and your intended use is not permitted by statutory regulation or exceeds the permitted use, you will need to obtain permission directly from the copyright holder. To view a copy of this licence, visit http://creativecommons.org/licenses/by/4.0/. The Creative Commons Public Domain Dedication waiver (http://creativecommons.org/publicdomain/zero/1.0/) applies to the data made available in this article, unless otherwise stated in a credit line to the data. 


\section{Background}

Timely initiation of breastfeeding has lifetime importance for the mother and the child [1,2] and the Global Strategy for Infant and Young Child Feeding (GSIYF) sets the standards for timelyinitiation of breastfeeding [3]. Specifically, the GSIYF standards include 6 months of exclusive breastfeeding, and continued breastfeeding for 2 years or beyond with, timely, adequate, safe and appropriate complementary foods starting after 6 months. Related support for maternal health, nutrition and birth spacing is also important [3].

Globally, timely initiation of breastfeeding is low (44\%) [4]. Newborns whose mothers do not initiate breastfeeding after the first hour of birth (33\%) face a greater risk of common infections [5], have 50\% increased risk of breathing difficulties in the first 6 months of life and increased risk of death compared with those whose mothers begin breastfeeding within 1 hour of birth [6, 7]. The risk of death increases with increasing delay in initiation of breastfeeding from 1 hour to day seven [5]. The first hour is important because it is within this period that newborns can be fed on colostrum (the first breast milk that provide passive and active protection against a wide variety of known pathogens) [8]. Thus, initiation of breastfeeding within the first 1 hour of delivery, is vital and can reduce neonatal mortality by $19.1 \%$ [9].

Studies have revealed a number of maternal and child factors as associated with timely initiation of breastfeeding. Ghimire [10] in a study among women of Nepal, indicated that educational level, ethnicity, mother's involvement in agricultural occupations, and delivery in a health facility were associated with timely initiation of breastfeeding. Also, in Nepal, Adhikari [9] reported that the size of babies at birth and place of residence were associated with timely initiation of breastfeeding. Furthermore, Sigman-Grant and Kim [11] revealed that traditional beliefs and knowledge about specific breastfeeding are also linked to timely initiation of breastfeeding in Brisbane and Perth in Australia.

While some studies on timely initiation of breastfeeding in Africa have been published [1,12-14], there is a dearth of studies linking maternal and child factors with timely initiation of breastfeeding across sub-Saharan Africa (SSA). Thus, we sought to examine the maternal and child factors associated with timely initiation of breastfeeding in SSA. Findings from the study may give a better understanding for policy interventions geared towards enhancing timely initiation of breastfeeding.

\section{Methods}

\section{Data source}

We pooled data from the most recent Demographic and Health Surveys (DHSs) of 29 countries in SSA from
2010 to 2018. Specifically, we used data from the child's recode file of the various countries. The DHS is a nationally representative survey that has been conducted in over 85 low-and middle-income countries globally. It focuses on essential maternal and child health markers including "breastfeeding practices" [15]. The survey employs a two-stage stratified sampling technique, which makes the data nationally representative. The first-stage sampling consisted of a list of primary sampling units (PSUs) or enumeration areas (EAs) that covered the entire country and usually were obtained from the latest national census, when available. EAs are further subdivided into standard size segments of about 100-500 households per segment. In this stage, a sample of predetermined segments is selected randomly with probability proportional to the EA's size (number of households in EA). In the second stage, the DHS personnel select households systematically from a list of previously enumerated households in each selected EA segment, and in-person interviews were conducted in selected households to target populations: women aged 15-49, men aged 15-64, and children under five. The women, those who were usual residents of selected households or visitors who slept in the households on the night before the survey are interviewed. Data on timely initiation of breastfeeding were obtained from the women through self-reporting. Aliaga and Ruilin, [16] provides details of the sampling process. A total of 60 , 038 women aged 15-49 years with birth history and who had children born in the 2 years preceding the survey and practiced breastfeeding were included in our study. We excluded women without birth history, those who did not give birth in the 2 years preceding the survey and those with no information on breastfeeding. As shown in Table 1, the overall number of missing values, was 2954, which represented $4.68 \%$ of the total sample. Due to the small proportion of missing values, we used complete cases for the analysis. We relied on the Strengthening the Reporting of Observational Studies in Epidemiology' (STROBE) statement in writing the manuscript [17].

\section{Definition of variables \\ Outcome variable}

The outcome variable for the study was timely initiation of breastfeeding. It was derived from the question, "How long after birth did you first put (NAME) to the breast?" The responses were: immediately, hours and days [18, 19]. The responses were then dichotomised to timely initiation of breastfeeding $=1$, if women responded that breastfeeding was done immediately after birth or within 
Table 1 Description of surveys and sample sizes

\begin{tabular}{|c|c|c|c|c|c|}
\hline Country & Survey year & Sample $^{\mathrm{a}}$ & Sample ${ }^{b}$ & Sample & Sample ${ }^{d}$ \\
\hline Angola & $2015-16$ & 14,322 & 3043 & 1402 & 1394 \\
\hline Burkina Faso & 2017-18 & 15,044 & 2885 & 2972 & 2909 \\
\hline Benin & 2010 & 13,407 & 4943 & 4417 & 4413 \\
\hline Burundi & 2015-16 & 13,192 & 2591 & 2703 & 2609 \\
\hline Congo DR & 2018 & 18,716 & 3704 & 3663 & 3452 \\
\hline Congo & 2015 & 9329 & 2067 & 1064 & 1005 \\
\hline Cameroon & 2012 & 11,732 & 2441 & 1568 & 1470 \\
\hline Ethiopia & $2011-12$ & 10,641 & 4016 & 4255 & 4096 \\
\hline Gabon & 2013-14 & 6067 & 1682 & 235 & 212 \\
\hline Ghana & 2016 & 5884 & 1218 & 1222 & 1171 \\
\hline Gambia & 2012 & 8088 & 1677 & 1654 & 1596 \\
\hline Guinea & 2013 & 7039 & 1447 & 1471 & 1429 \\
\hline Kenya & 2014 & 20,964 & 7861 & 3581 & 3402 \\
\hline Comoros & 2018 & 3149 & 1259 & 1253 & 1129 \\
\hline Liberia & 2014 & 7606 & 1499 & 1310 & 1281 \\
\hline Lesotho & 2014 & 3138 & 655 & 640 & 204 \\
\hline Malawi & 2013 & 17,286 & 2207 & 1990 & 1878 \\
\hline Mali & 2016 & 10,326 & 1960 & 2214 & 2138 \\
\hline Niger & 2018 & 12,558 & 2283 & 2442 & 2334 \\
\hline Namibia & 2013 & 5046 & 952 & 861 & 819 \\
\hline Rwanda & 2012 & 7856 & 1524 & 1580 & 1526 \\
\hline Sierra Leone & 2015 & 11,938 & 2150 & 2204 & 2108 \\
\hline Senegal & 2017 & 12,326 & 1908 & 1764 & 1710 \\
\hline Chad & 2013 & 18,623 & 4217 & 4287 & 4052 \\
\hline Togo & 2016 & 6979 & 1395 & 874 & 838 \\
\hline Tanzania & 2014 & 10,233 & 4163 & 4123 & 3964 \\
\hline Uganda & 2016 & 15,522 & 1954 & 1924 & 1811 \\
\hline Zambia & 2018 & 13,457 & 5043 & 2959 & 2793 \\
\hline Zimbabwe & 2015 & 6132 & 2240 & 2355 & 2293 \\
\hline Total & & 316,600 & 74,984 & 62,992 & 60,038 \\
\hline
\end{tabular}

aAll children under-five; ${ }^{b}$ children under 2 years; ${ }^{c}$ children whose mothers had information on breastfeeding; ${ }^{d}$ children whose mothers had complete information on all variables of interest

the first hour, and late initiation $=0$, if women responded otherwise $[18,19]$.

\section{Independent variables}

The study used seventeen independent variables. These variables were considered principally because of their statistically significant relationship with timely initiation of breastfeeding in previous studies [12-14, 18, 19]. These variables were grouped into maternal factors child factors and contextual factor. The maternal factors included mother's age, mother's educational level, marital status, employment status, frequency of reading newspaper, frequency of listening to radio, frequency of watching television, number of antenatal care (ANC) visits, place of residence, wealth quintile, type of delivery assistance, place child was delivered, and type of delivery. Wealth quintile is computed based on household assets and characteristics of the household. In DHS, wealth quintile is computed using Principal Component Analysis (PCA). The child factors used for the study were size of the child at birth, birth order and twin status of the child (Table 2). The contextual factor was sub-region and was grouped into West Africa, South Africa, Central Africa, and East Africa.

\section{Statistical analyses}

The data were analysed with Stata version 14.0 (Stata Corporation, College Station, TX, USA). The analyses were done in three steps. The first step was the computation of the prevalence of timely initiation of breastfeeding in SSA. The second step was a bivariate analysis that calculated the proportions of timely initiation of breastfeeding across the socio-demographic characteristics with their significance levels. After the bivariate analysis, we checked for high correlation among the significant explanatory variables through a test for multicollinearity using the variance inflation factor (VIF) and the results showed no evidence of high collinearity (Mean VIF $=1.47$, Maximum $\mathrm{VIF}=2.76$, and Minimum VIF $=1.02$ ). Afterwards, three hierarchical logistic regression models were built. Only variables that were significant from the second step were used in a multivariable logistic regression (Table 3). Model I constituted a multivariable analysis between the maternal factors and timely initiation of breastfeeding. We added child factors to the initial model in Model II. Model III controlled for the effect of sub-regions. We presented all results of the logistic analyses as adjusted odds ratios (aORs) with 95\% confidence intervals (CIs). All frequency distributions were weighted using the sample weight (v005/1,000,000) whiles the svy command was used to account for the complex survey design and generalizability of the findings.

\section{Results}

Prevalence of timely initiation of breastfeeding in subSaharan Africa

Figure 1 presents results on the prevalence of timely initiation of breastfeeding in SSA. We found a prevalence of $55.81 \%$ in the sub-region. The country with the highest prevalence of timely initiation of breastfeeding was Burundi (86.19\%), whereas Guinea had the lowest prevalence (15.17\%).

\section{Bivariate results on the determinants of timely initiation of breastfeeding}

Table 2 presents results of the distribution of timely initiation of breastfeeding in SSA accross the explanatory 
Table 2 Distribution of timely initiation of breastfeeding in SSA by explanatory variables (Weighted, $N=60,038$ )

\begin{tabular}{llll}
\hline Variables & Weighted $\boldsymbol{N}$ & Weighted \% & Tim \\
\hline Mother's age & & & \\
$15-19$ & 6122 & 10.2 & 50.6 \\
$20-24$ & 14,954 & 24.9 & 55.4 \\
$25-29$ & 16,200 & 27.0 & 57.1 \\
$30-34$ & 11,723 & 19.5 & 57.1 \\
$35-39$ & 7439 & 12.4 & 56.6 \\
$40-44$ & 2953 & 4.9 & 56.7 \\
$45-49$ & 647 & 1.1 & 57.8
\end{tabular}

\section{Marital status}

Never married
Married
Cohabiting
Widowed
Divorced

Mother's educational level

Secondary+

Working

Urban

Rural

44,184

73.6

Wealth quintile

Poorest

14,547

Poorer

13,394

12,079

Middle

10,949

Richer

9069

Richest

Frequency of reading newspaper

Not at all

51,638

Less than once a week

At least once a week

5206

3194

Frequency of listening to radio

Not at all

Less than once a week

At least once a week

21,000

Frequency of watching television

Not at all

Less than once a week

At least once a week

11,309

Number of ANC visits 
Table 2 Distribution of timely initiation of breastfeeding in SSA by explanatory variables (Weighted, $N=60,038)($ Continued)

\begin{tabular}{|c|c|c|c|c|}
\hline Variables & Weighted $N$ & Weighted \% & Timely initiation of breastfeeding & $P$ - value \\
\hline $1-3$ & 21,951 & 36.6 & 56.1 & \\
\hline $4+$ & 31,961 & 53.2 & 57.5 & \\
\hline Size of child at birth & & & & $183.3(<0.001)$ \\
\hline Larger than average & 20,636 & 34.4 & 54.3 & \\
\hline Average & 28,955 & 48.2 & 58.6 & \\
\hline Smaller than average & 10,446 & 17.4 & 51.7 & \\
\hline Birth order & & & & $100.4(<0.001)$ \\
\hline 1 st & 12,563 & 20.9 & 53.2 & \\
\hline $2-4$ & 28,640 & 47.7 & 58.0 & \\
\hline $5+$ & 18,835 & 31.4 & 54.6 & \\
\hline Place of delivery & & & & $701.3(<0.001)$ \\
\hline Home & 20,329 & 33.9 & 48.5 & \\
\hline Health facility & 39,709 & 66.1 & 59.8 & \\
\hline Assisted by a health worker & & & & $171.9(<0.001)$ \\
\hline No & 26,164 & 41.9 & 49.6 & \\
\hline Yes & 34,874 & 53.1 & 60.6 & \\
\hline Type of delivery & & & & $569.8(<0.001)$ \\
\hline Vaginal birth & 56,987 & 94.9 & 57.0 & \\
\hline Cesarean section & 3051 & 5.1 & 34.6 & \\
\hline Twin status & & & & $49.3(<0.001)$ \\
\hline Single birth & 59,028 & 98.3 & 56.1 & \\
\hline Multiple birth & 1010 & 1.7 & 45.1 & \\
\hline
\end{tabular}

variables. All the explanatory variables, except place of residence had significant associations with timely initiation of breastfeeding at $95 \% \mathrm{CI}$. The highest prevalence of timely initiation of breastfeeding was among women aged 45-49 (57.8\%), those who were widowed (58.4\%), women with primary education (59.0\%), non-working women (57.3\%), those with richest wealth quintile (58.7\%), those who read newspaper less than once a week (59.3\%), those who listened to radio at least once a week (57.3\%), and those who never watched television (56.6\%). Women who had four or more ANC visits (57.5\%), those with average sized children (58.6\%), those with 2-4 birth order children (58.0\%), those who delivered in the health facility (59.8\%), those who had assistance of a health professional during delivery (60.6\%), those who had vaginal delivery $(57.0 \%)$, and those with single births $(56.1 \%)$, all had high prevalence of timely initiation of breastfeeding.

\section{Results of the multivariable logistic regression analysis}

Table 3 presents results of the multivariable hierarchical logistic regression analysis on the maternal and child factors associated with timely initiation of breastfeeding in SSA. Model III, which is the complete model, presents the results for all the determinants, while controlling for sub-regions. The results show that the likelihood of timely initiation of breastfeeding was higher among women of all age categories compared with those aged 15-19, with the highest odds among those aged 45-49 (aOR 1.63; 95\% CI 1.36, 1.94). Richest women were more likely to practice timely initiation of breastfeeding compared to women with poorest wealth quintile (aOR 1.13 ; $95 \%$ CI 1.05, 1.20). Higher odds of timely initiation of breastfeeding were also observed among women with primary education (aOR 1.21; 95\% CI 1.16, 1.26), those who read newspaper at least once a week (aOR 1.13; $95 \%$ CI 1.06, 1.21), women who had four or more ANC visits (aOR 1.11; 95\% CI 1.03, 1.17) and women who delivered at the health facility (aOR 1.41; 95\% CI 1.33, $1.50)$, compared to women with no formal education, those who never read newspaper, those with no ANC visits and those who delivered at home. Women who were assisted by a health professional during delivery, compared to those who were not (aOR 1.26; 95\% CI $1.19,1.33)$, those who had 2-4 birth order children compared to those with first birth order children (aOR 1.15; $95 \%$ CI 1.09, 1.21) and women who lived in Southern Africa compared to those who lived in West Africa (aOR 2.13 ; $95 \%$ CI $1.97,2.31$ ) were more likely to initiate breastfeeding timely. 


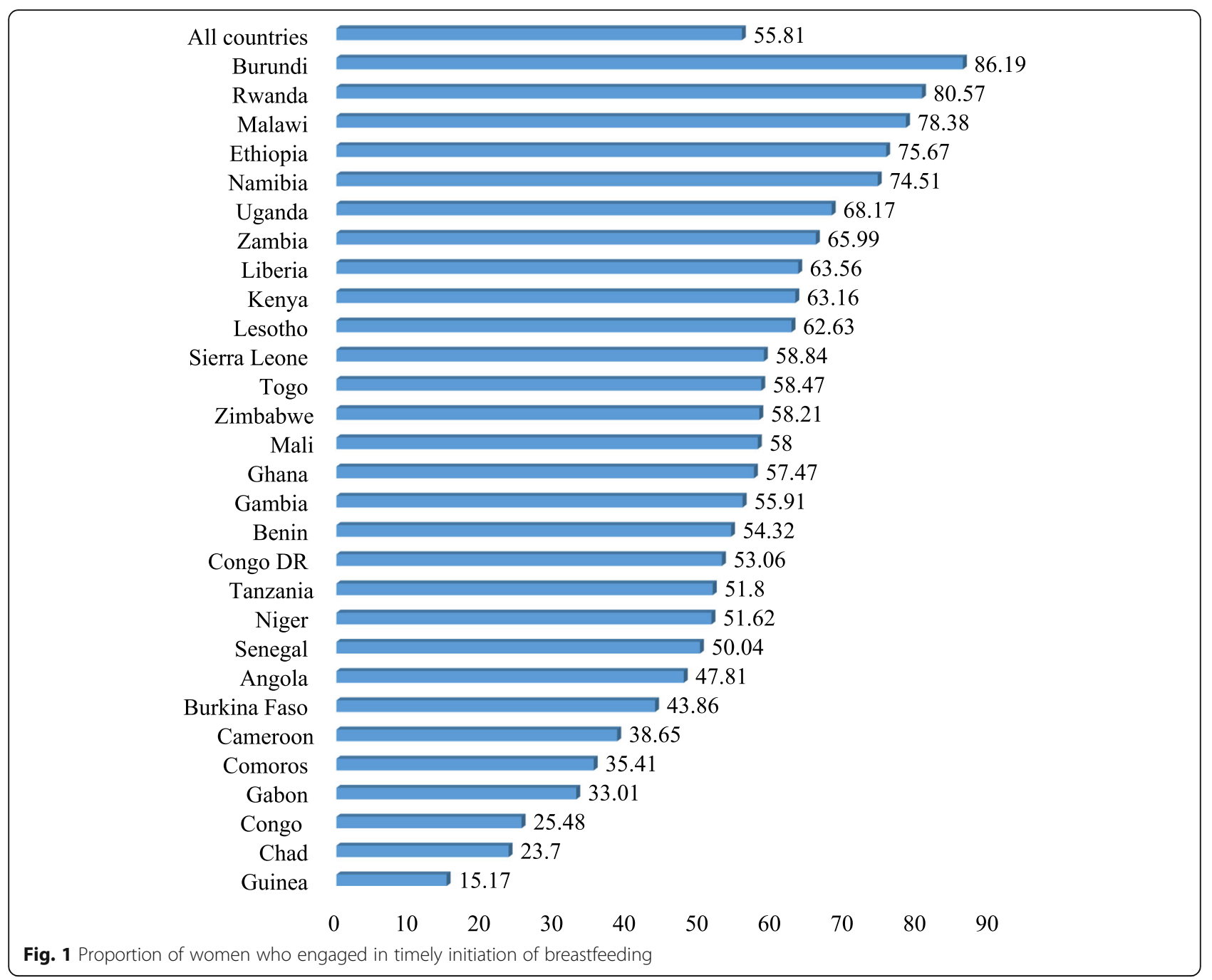

Lower odds of timely initiation of breastfeeding were identified in married women, compared to never married women (aOR 0.91; 95\% CI 0.85, 0.98); working women, compared to non-working women (aOR 0.90; 95\% CI $0.87,0.93)$; women who listened to radio less than once a week, compared to those who never listened to radio (aOR 0.93; 95\% CI 0.88, 0.97); women who watched television at least once a week, compared to those who never watched television (aOR 0.74; 95\% CI 0.70, 0.78); women who delivered through caesarean section, compared to those who had vaginal delivery (aOR 0.30; 95\% CI $0.27,0.32$ ); women who had smaller than average children compared to those with larger than average children (aOR 0.94; 95\% CI 0.90, 0.99); and those with multiple births, compared to those with single births (aOR 0.67; 95\% CI 0.59, 0.76). Women who lived in Central Africa were less likely to initiate breastfeeding timely compared to those who lived in West Africa (aOR 0.80 ; $95 \%$ CI $0.75,0.84$ ).

\section{Discussion}

The study sought to examine the maternal and child factors associated with timely initiation of breastfeeding in SSA. The results indicated that timely initiation of breastfeeding was phenomenal among Southern and East Africans. A meta-analysis conducted by Issaka and colleagues about the prevalence of key breastfeeding indicators in 29 sub-Saharan African countries similarly found that women in Southern Africa were inclined to timely initiation of breastfeeding [12]. Hence, underlying factors influencing mothers' timely initiation of breastfeeding practices across SSA need a critical attention. Meanwhile, a review by Bora [20] noted that educational interventions significantly increased breastfeeding rates in developing countries. Therefore, similar interventions could aid improve maternal knowledge and practices of timely initiation of breastfeeding among women in SSA, especially residents in Central Africa. In relation to the above, the present study identified specific maternal and 
Table 3 Multivariable hierarchical logistic regression analysis on determinants of timely initiation of breastfeeding in SSA

\begin{tabular}{|c|c|c|c|}
\hline Variable & $\begin{array}{l}\text { Model I } \\
\text { aOR 95\% Cl }\end{array}$ & $\begin{array}{l}\text { Model II } \\
\text { aOR } 95 \% \mathrm{Cl}\end{array}$ & $\begin{array}{l}\text { Model III } \\
\text { aOR } 95 \% \mathrm{Cl}\end{array}$ \\
\hline \multicolumn{4}{|l|}{ Mother's age } \\
\hline $15-19$ & 1 & 1 & 1 \\
\hline $20-24$ & $1.26^{* * *}(1.18,1.34)$ & $1.20^{* * *}(1.13,1.28)$ & $1.18^{* * *}(1.10,1.26)$ \\
\hline $25-29$ & $1.40^{* * *}(1.32,1.49)$ & $1.35^{* * *}(1.26,1.46)$ & $1.32^{* * *}(1.22,1.42)$ \\
\hline $30-34$ & $1.41^{* * *}(1.32,1.51)$ & $1.45^{* * *}(1.34,1.58)$ & $1.38^{* * *}(1.27,1.50)$ \\
\hline $35-39$ & $1.41^{* * *}(1.31,151)$ & $1.51^{* * *}(1.38,1.65)$ & $1.43^{* * *}(1.30,1.56)$ \\
\hline $40-44$ & $1.44^{* * *}(1.31,157)$ & $1.56^{* * *}(1.40,1.74)$ & $1.49^{* * *}(1.33,1.66)$ \\
\hline $45-49$ & $1.56^{* * *}(1.33,1.84)$ & $1.71^{* * *}(1.44,2.04)$ & $1.63^{* * *}(1.36,1.94)$ \\
\hline \multicolumn{4}{|l|}{ Wealth quintile } \\
\hline Poorest & 1 & 1 & 1 \\
\hline Poorer & $0.97(0.93,1.02)$ & $0.97(0.921,1.01)$ & $0.99(0.94,1.03)$ \\
\hline Middle & $1.01(0.96,1.06)$ & $1.01(0.96,1.06)$ & $1.02(0.97,1.07)$ \\
\hline Richer & $1.03(0.98,1.09)$ & $1.02(0.97,1.08)$ & $1.02(0.97,1.08)$ \\
\hline Richest & $1.19^{* * *}(1.011,1.27)$ & $1.17^{* * *}(1 \cdot 10,1.25)$ & $1.13^{* * *}(1.05,1.20)$ \\
\hline \multicolumn{4}{|l|}{ Marital status } \\
\hline Never married & 1 & 1 & 1 \\
\hline Married & $0.98(0.91,1.06)$ & $0.96(0.89,1.03)$ & $0.91^{*}(0.85,0.98)$ \\
\hline Cohabiting & $0.86^{* * *}(0.79,0.93)$ & $0.84^{* * * *}(0.78,0.91)$ & $0.87^{* *}(0.80,0.95)$ \\
\hline Widowed & $1.04(0.87,1.25)$ & $1.02(0.84,1.22)$ & $1.00(0.83,1.20)$ \\
\hline Divorced & $0.94(0.85,1.05)$ & $0.92(0.83,1.02)$ & $0.90^{*}(0.81,1.00)$ \\
\hline \multicolumn{4}{|l|}{ Mother's education level } \\
\hline No education & 1 & 1 & 1 \\
\hline Primary & $1.22^{* * *}(1.17,1.27)$ & $1.21^{* * *}(1.16,1.26)$ & $1.21^{* * *}(1.16,1.26)$ \\
\hline Secondary+ & $1.03(0.97,1.08)$ & $1.02(0.96-1.07)$ & $1.03(0.98,1.09)$ \\
\hline \multicolumn{4}{|l|}{ Employment status } \\
\hline Not working & 1 & 1 & 1 \\
\hline Working & $0.85^{* * *}(0.82,0.88)$ & $0.85^{* * *}(0.82,0.88)$ & $0.90^{* * *}(0.87,0.93)$ \\
\hline \multicolumn{4}{|c|}{ Frequency of reading newspaper } \\
\hline Not at all & 1 & 1 & 1 \\
\hline Less than once a week & $1.14^{* * *}(1.07,1.22)$ & $1.13^{* * *}(1.06,1.21)$ & $1.13^{* * *}(1.06,1.21)$ \\
\hline At least once a week & $1.07(0.98,1.16)$ & $1.06(0.97,1.15)$ & $1.09^{*}(1.00,1.19)$ \\
\hline \multicolumn{4}{|c|}{ Frequency of listening to radio } \\
\hline Not at all & 1 & 1 & 1 \\
\hline Less than once a week & $0.96(0.92,1.01)$ & $0.96(0.92,1.01)$ & $0.93^{* *}(0.88,0.97)$ \\
\hline At least once a week & $1.07^{* * *}(1.02,1.11)$ & $1.06^{* *}(1.02,1.10)$ & $1.03(0.99,1.07)$ \\
\hline \multicolumn{4}{|c|}{ Frequency of watching to television } \\
\hline Not at all & 1 & 1 & 1 \\
\hline Less than once a week & $0.81^{* * *}(0.77,0.87)$ & $0.82^{* * *}(0.78,0.87)$ & $0.82^{* * *}(0.77,0.86)$ \\
\hline At least once a week & $0.71^{* * *}(0.67,0.75)$ & $0.70^{* * * *}(0.67,0.74)$ & $0.74^{* * *}(0.70,0.78)$ \\
\hline \multicolumn{4}{|l|}{ Number of ANC visits } \\
\hline 0 & 1 & 1 & 1 \\
\hline $1-3$ & $1.13^{* * *}(1.07,1.20)$ & $1.12^{* * *}(1.05,1.19)$ & $1.10^{* *}(1.03,1.17)$ \\
\hline $4+$ & $1.15^{* * *}(1.08,1.22)$ & $1.13^{* * *}(1.07,1.20)$ & $1.11^{* *}(1.03,1.17)$ \\
\hline
\end{tabular}


Table 3 Multivariable hierarchical logistic regression analysis on determinants of timely initiation of breastfeeding in SSA (Continued)

\begin{tabular}{|c|c|c|c|}
\hline Variable & $\begin{array}{l}\text { Model I } \\
\text { aOR 95\% Cl }\end{array}$ & $\begin{array}{l}\text { Model II } \\
\text { aOR } 95 \% \mathrm{Cl}\end{array}$ & $\begin{array}{l}\text { Model III } \\
\text { aOR } 95 \% \mathrm{Cl}\end{array}$ \\
\hline \multicolumn{4}{|l|}{ Place of delivery } \\
\hline Home & 1 & 1 & 1 \\
\hline Health facility & $1.32^{* * *}(1.24,1.39$ & $1.29^{* * *}(1.22,1.37)$ & $1.41^{* * *}(1.33,1.50)$ \\
\hline \multicolumn{4}{|c|}{ Assisted by a health worker during delivery } \\
\hline No & 1 & 1 & 1 \\
\hline Yes & $1.39^{* * *}(1.32,1.47)$ & $1.41^{* * *}(1.34,1.49)$ & $1.26^{* * *}(1.19,1.33)$ \\
\hline \multicolumn{4}{|l|}{ Type of delivery } \\
\hline Vaginal birth & 1 & 1 & 1 \\
\hline Cesarean section & $0.31^{* * *}(0.28,0.33)$ & $0.31^{* * * *}(0.29,0.34)$ & $0.30^{* * *}(0.27,0.32)$ \\
\hline \multicolumn{4}{|l|}{ Size of child at birth } \\
\hline Larger than average & & 1 & 1 \\
\hline Average & & $1.20^{* * *}(1.15,1.24)$ & $1.19^{* * *}(1.15,1.24)$ \\
\hline Smaller than average & & $0.97(0.92,1.02)$ & $0.94^{*}(0.90,0.99)$ \\
\hline \multicolumn{4}{|l|}{ Birth order } \\
\hline $1 s t$ & & 1 & 1 \\
\hline $2-4$ & & $1.13^{* * *}(1.07,1.19)$ & $1.15^{* * *}(1.09,1.21)$ \\
\hline $5+$ & & $0.93^{*}(0.87,1.00)$ & $0.97(0.90,1.04)$ \\
\hline \multicolumn{4}{|l|}{ Twin status } \\
\hline Single birth & & 1 & 1 \\
\hline Multiple birth & & $0.65^{* * *}(0.57,0.74)$ & $0.67^{* * *}(0.59,0.76)$ \\
\hline \multicolumn{4}{|l|}{ Sub Region } \\
\hline West Africa & & & 1 \\
\hline East Africa & & & $1.71^{* * *}(1.64,1.78)$ \\
\hline Central Africa & & & $0.80^{* * *}(0.75,0.84)$ \\
\hline Southern African & & & $2.13^{* * *}(1.97,2.31)$ \\
\hline $\mathbf{N}$ & 60,038 & 60,038 & 60,038 \\
\hline Pseudo $\mathrm{R}^{2}$ & 0.027 & 0.030 & 0.046 \\
\hline
\end{tabular}

Exponentiated coefficients; $95 \%$ confidence intervals in brackets

${ }^{*} p<0.05,{ }^{* *} p<0.01,{ }^{* * *} p<0.001$

aOR Adjusted Odds Ratio, $\mathrm{Cl}$ Confidence Interval

Model I: Maternal factors

Model II: Child factors

Model III: Maternal factors, child factors and sub-region

child factors associated with timely initiation of breastfeeding.

The study revealed that maternal socio-economic status was positively associated with timely initiation of breastfeeding. The results are consistent with a systematic review of literature on factors and barriers accounting for timely initiation of breastfeeding in South Asia [21]. Also, birth order correlated with timely initiation of breastfeeding whereby women at parity 2-4 had higher odds to initiate breastfeeding timely. Probably, women of higher parity might be refining their knowledge and practices about breastfeeding with each birth [1], hence, affecting their breastfeeding practices. Consistent with a previous study [9], timely initiation of breastfeeding correlated with women who delivered at the health facility. Similarly, the study revealed a positive association between health worker's assisted delivery and timely initiation of breastfeeding. This is not surprising since mothers who delivered in the health facilities can benefit from direct counselling provided by health professionals on the practice of timely initiation of breastfeeding [10].

In disagreement to a previous study [9], the prevailing study observed a negative association between mother's level of education and timely initiation of breastfeeding. Arguably, education propels women to be receptive to health information which refines their behavior and reorient them to select positive health behaviours, including adopting healthy infant feeding practices such as 
timely initiation of breastfeeding [22], so our observation was unexpected. Moreover, an inverse relationship was noted between access to radio and timely initiation of breastfeeding. Theoretically, having access to information through radio might not necessarily translate into usage of such information if the information is culturally incompatible and complex to adopt [23]. Other maternal factors that determined timely initiation of breastfeeding include marital status and ANC visits. Although, a study conducted across nine countries in SSA had reported that when mothers attended ANC frequently, their likelihood to timely initiate breastfeeding increased [24]. However, the cross-sectional nature of the present study limited the effort to explain the reasons accounting for this relationship. Therefore, further studies to explain the relationship between these maternal variables and timely initiation of breastfeeding will be beneficial.

The study noted an inverse association between child's birthweight and timely initiation of breastfeeding, whereby decreasing odds to timely initiate breastfeeding was found among women with children smaller than average size. Plausibly, some of the children born underweight may be undergoing the continuous maturing process of the physiologic functions relating to 'nutritive sucking pathway' development [25]. Hence, limiting their abilities needed for breastfeeding within the first hour of life, including having a good coordination of the suction-deglutition respiration cycle and the breastseeking reflex [26]. Delivering through caesarean section was negatively associated with timely initiation of breastfeeding. Yisma et al. in their meta-analysis about impact of caesarean section on breastfeeding indicators among 33 countries in sub-Saharan Africa, showed that caesarean section was associated with a $46 \%$ lower prevalence of timely initiation of breastfeeding [14]. It is argued that mothers undergo a lot of pain due to caesarean delivery which contribute to the delay in breastfeeding practice [26]. Other literature also suggest that effects of anaesthesia could delay the onset of lactation or babies delivered through caesarean section faces associated respiratory distress [1]. Finally, the study revealed an inverse association between multiple births and timely initiation of breastfeeding. It is known that mothers who deliver multiple babies often experience difficulty with the initiation of breastfeeding during their hospitalisation [27]. Furthermore, the birth of twin babies is physically and mentally demanding compared to a singleton birth and is associated with numerous obstacles to breastfeeding [28].

\section{Strengths and limitations}

The novelty and strength linked with this study stem from the fact that, it investigated both maternal and child factors associated with timely initiation of breastfeeding in SSA using a nationally representative survey datasets from 29 countries. Also, the probability method employed in selecting survey respondents matched with appropriate analytical procedure make the results of the study robust. Again, the two-stage sampling approach used ensured that there was no selection bias that could affect the results. However, our results should be interpreted with caution. Firstly, causality cannot be established due to the cross-sectional nature of the study. Again, some variables had missing data that were treated as complete cases. Notwithstanding, the final sample size used, had a higher response rate which masked the effect of missing data. Also, the time interval between delivery and the interview up to 5 years can lead to recall bias which can result in inaccurate responses from mothers regarding the timeframe they put their babies to breastmilk. Additionally, surveyed women might provide responses concerning the practices of timely initiation of breastfeeding with the view of creating a positive breastfeeding image for themselves among those who know it is desirable, hence, social desirability bias is unavoidable in this study. Again, the interpretation of the odds should be done with caution as we admit that the higher odds ratios obtained in relation with some of the variables could be due to the large sample size used in this study. Moreover, the percentage variance in the models could have been increased by the inclusion of some sociocultural variables like colonial past, which were not available in the datasets. Finally, we admit that our study design did not permit us to investigate the reasons why disparities occurred, as far as timely initiation of breastfeeding and maternal and child factors are concerned.

\section{Conclusions}

The maternal factors identified to influence timely initiation of breastfeeding were mother's wealth quintile, educational attainment, employment status, type of delivery assistance, place of delivery, type of delivery, marital status, ANC visits, and country of residence. The associated child factors were child's size at birth, birth order and twin status. It is recommended that prioritising policies to enhance timely initiation of breastfeeding is needed, particularly among Central African countries where timely initiation of breastfeeding remains a challenge. Sufficient supportive care in addition to guidance and counselling should be given to mothers, especially those who go through caesarean section, deliver children smaller than average size or encounter multiple births to resolve timely initiation of breastfeeding inequalities associated with such class of mothers. Behavioural change communication programmes targeted at timely initiation of breastfeeding to reverse and close the timely initiation of breastfeeding gaps stratified 


\section{by the maternal and child factors is worth implemented in SSA.}

\section{Abbreviations}

ANC: Antenatal Care; Cl: Confidence interval; CS: Caesarean section; DHS: Demographic and Health Surveys; EA: Enumeration areas; GSIYF: Global Strategy for Infant and Young Child Feeding; SSA: Sub-Saharan Africa: STROBE: Strengthening the Reporting of Observational Studies in Epidemiology; VIF: Variance inflation factor; WHO: World Health Organization

\section{Acknowledgements}

We acknowledge Measure DHS for providing us with the data upon which the findings of this study were based.

\section{Authors' contributions}

FA conceptualized the study. BOA and EB conducted the statistical analysis. $F A, B O A, E B, J K O, F S, B L, E K A$ and $A S$ contributed to the design of the first draft. FA, BOA, EB, JKO, FS, BL, EKA and AS contributed to the revision of the manuscript. All authors contributed equally in drafting the manuscript. All authors read and approved the final manuscript. AS had the final responsibility to submit the manuscript.

\section{Funding}

The authors did not obtain funding for this project.

\section{Availability of data and materials}

The dataset is freely available for download at: https://dhsprogram.com/data/ available-datasets.cfm.

\section{Declarations}

\section{Ethics approval and consent to participate}

The DHS reports that ethical clearances were obtained from the Ethics Committee of ORC Macro Inc. as well as Ethics Boards of partner organisations of the various countries such as the Ministries of Health. The DHS follows the standards for ensuring the protection of respondents' privacy. ICF International ensures that the survey complies with the U.S. Department of Health and Human Services' regulations for the respect of human subjects. This was a secondary analysis of data and therefore no further approval was required since the data is available in the public domain. Further information about the DHS data usage and ethical standards are available at http://goo.gl/ny8T6X.

\section{Consent for publication}

Not applicable.

\section{Competing interests}

The authors declare that they have no competing interests.

\section{Author details}

'Department of Population and Health, College of Humanities and Legal Studies, University of Cape Coast, Cape Coast, Ghana. ${ }^{2}$ Berekum College of Education, Berekum, Bono Region, Ghana. ${ }^{3}$ Faculty of Health, School of Public Health, University of Technology Sydney, Ultimo, NSW, Australia. ${ }^{4}$ Department of Health, Physical Education, and Recreation, University of Cape Coast, Cape Coast, Ghana. ${ }^{5}$ College of Public Health, Medical and Veterinary Sciences, James Cook University, Townsville, Queensland, Australia. ${ }^{6}$ Department of Estate Management, Takoradi Technical University, Takoradi, Ghana.

Received: 19 June 2020 Accepted: 5 July 2021

Published online: 19 July 2021

\section{References}

1. Belachew A. Timely initiation of breastfeeding and associated factors among mothers of infants age 0-6 months old in Bahir Dar City, northwest, Ethiopia, 2017: a community based cross-sectional study. Int Breastfeed J. 2019;14(1):5. https://doi.org/10.1186/s13006-018-0196-3.

2. Victora CG, Bahl R, Barros AJ, França GV, Horton S, Krasevec J, et al. Breastfeeding in the 21st century: epidemiology, mechanisms, and lifelong effect. Lancet. 2016;387(10017):475-90. https://doi.org/10.1016/50140-6736(1 5)01024-7.

3. World Health Organization. Global strategy for infant and young child feeding. Geneva: World Health Organization; 2003

4. UNICEF, WHO. Capture the moment - early initiation of breastfeeding: the best start for every newborn. New York: UNICEF; 2018.

5. Edmond KM, Kirkwood BR, Amenga-Etego S, Owusu-Agyei S, Hurt LS. Effect of early infant feeding practices on infection-specific neonatal mortality: an investigation of the causal links with observational data from rural Ghana. Am J Clin Nutr. 2007;86(4):1126-31. https://doi.org/10.1093/ajcn/86.4.1126.

6. Smith ER, Locks LM, Manji KP, McDonald CM, Kupka R, Kisenge R, et al. Delayed breastfeeding initiation is associated with infant morbidity. J Pediatr. 2017;191:57-62. https://doi.org/10.1016/j.jpeds.2017.08.069.

7. Khan J, Vesel L, Bahl R, Martines JC. Timing of breastfeeding initiation and exclusivity of breastfeeding during the first month of life: effects on neonatal mortality and morbidity - a systematic review and meta-analysis. Matern Child Health J. 2015;19(3):468-79. https://doi.org/10.1007/s10995014-1526-8.

8. WHO Collaborative Study Team. The role of breastfeeding on the prevention of childmortality due to infectious diseases in developing countries: a pooled analysis. Lancet. 2000;355:451-5.

9. Adhikari M, Khanal V, Karkee R, Gavidia T. Factors associated with early initiation of breastfeeding among Nepalese mothers: further analysis of Nepal demographic and health survey, 2011. Int Breastfeed J. 2014;9(1):21. https://doi.org/10.1186/s13006-014-0021-6.

10. Ghimire $U$. The effect of maternal health service utilization in early initiation of breastfeeding among Nepalese mothers. Int Breastfeed J. 2019;14(1):33. https://doi.org/10.1186/s13006-019-0228-7.

11. Sigman-Grant M, Kim Y. Breastfeeding knowledge and attitudes of Nevada health care professionals remain virtually unchanged over 10 years. J Hum Lact. 2016;32(2):350-4. https://doi.org/10.1177/0890334415609916.

12. Issaka Al, Agho KE, Renzaho AM. Prevalence of key breastfeeding indicators in 29 sub-Saharan African countries: a meta-analysis of demographic and health surveys (2010-2015). BMJ Open. 2017;7(10):e014145. https://doi.org/1 0.1136/bmjopen-2016-014145.

13. Bergamaschi N, Oakley L, Benova L. Is childbirth location associated with higher rates of favourable early breastfeeding practices in sub-Saharan Africa? J Glob Health. 2019:9(1):010417. https://doi.org/10.7189/jogh.09.01 0417.

14. Yisma E, Mol BW, Lynch JW, Smithers LG. Impact of caesarean section on breastfeeding indicators: within-country and meta-analyses of nationally representative data from 33 countries in sub-Saharan Africa. BMJ Open. 2019;9(9):e027497. https://doi.org/10.1136/bmjopen-2018-027497.

15. Corsi DJ, Neuman M, Finlay JE, Subramanian SV. Demographic and health surveys: a profile. Int J Epidemiol. 2012;41(6):1602-13. https://doi.org/10.1 093/ije/dys 184.

16. Aliaga A, Ruilin R. Cluster optimal sample size for demographic and health surveys. In: 7th International Conference on Teaching Statistics-ICOTS, vol. 7; 2006. p. 2-7.

17. Von Elm E, Altman DG, Egger M, Pocock SJ, Gøtzsche PC, Vandenbroucke $J P$. The strengthening the reporting of observational studies in epidemiology (STROBE) statement: guidelines for reporting observational studies. Ann Intern Med. 2007;147(8):573-7. https://doi.org/10.7326/0003-4 819-147-8-200710160-00010

18. John JR, Mistry SK, Kebede G, Manohar N, Arora A. Determinants of early initiation of breastfeeding in Ethiopia: a population-based study using the 2016 demographic and health survey data. BMC Pregnancy Childbirth. 2019; 19(1):69. https://doi.org/10.1186/s12884-019-2211-0.

19. Ahmed AE, Salih OA. Determinants of the early initiation of breastfeeding in the Kingdom of Saudi Arabia. Int Breastfeed J. 2019;14(1):13. https://doi. org/10.1186/s13006-019-0207-z.

20. Bora R. Breast feeding in developing countries: is there a scope for improvement. J Neonatal Biol. 2016;5:208.

21. Sharma IK, Byrne A. Early initiation of breastfeeding: a systematic literature review of factors and barriers in South Asia. Int Breastfeed J. 2016;11(1):17. https://doi.org/10.1186/s13006-016-0076-7.

22. Zhao Q, Huang ZJ, Yang S, Pan J, Smith B, Xu B. The utilization of antenatal care among rural-to-urban migrant women in Shanghai: a hospital-based cross-sectional study. BMC Public Health. 2012;12(1):1012. https://doi.org/1 0.1186/1471-2458-12-1012

23. Rogers EM. Diffusion of innovations. New York: Free Press; 2003. 
24. Ogbo FA, Eastwood J, Page A, Efe-Aluta O, Anago-Amanze C, Kadiri EA, et al. The impact of sociodemographic and health-service factors on breastfeeding in sub-Saharan African countries with high diarrhoea mortality. Public Health Nutr. 2017:20:31-42.

25. Lau C. Development of suck and swallow mechanisms in infants. Ann Nutr Metab. 2015;66(Suppl 5):7-14. https://doi.org/10.1159/000381361.

26. Walker M. Breastfeeding the late preterm infant. J Obstet Gynecol Neonatal Nurs. 2008;37(6):692-701. https://doi.org/10.1111/j.1552-6909.2008.00293.x.

27. Mukunya D, Tumwine JK, Nankabirwa V, Ndeezi G, Odongo I, Tumuhamye J, et al. Factors associated with delayed initiation of breastfeeding: a survey in northern Uganda. Glob Health Action. 2017;10:141.

28. Kim BY. Factors that influence early breastfeeding of singletons and twins in Korea: a retrospective study. Int Breastfeed J. 2016;12(1):4. https://doi.org/1 0.1186/s13006-016-0094-5.

\section{Publisher's Note}

Springer Nature remains neutral with regard to jurisdictional claims in published maps and institutional affiliations.

Ready to submit your research? Choose BMC and benefit from:

- fast, convenient online submission

- thorough peer review by experienced researchers in your field

- rapid publication on acceptance

- support for research data, including large and complex data types

- gold Open Access which fosters wider collaboration and increased citations

- maximum visibility for your research: over $100 \mathrm{M}$ website views per year

At $\mathrm{BMC}$, research is always in progress.

Learn more biomedcentral.com/submissions 